\title{
A Educação Ambiental no currículo da escola do campo: propostas pedagógicas de uma Escola Família Agrícola
}

Environmental Education in the school of rural curriculum: pedagogical proposals of a Agricultural Family School

\author{
Fernanda Tesch Coelho \\ Marcos da Cunha Teixeira \\ Franklin Noel dos Santos
}

Resumo: Esta pesquisa teve como objetivo investigar como a Educação Ambiental está presente nas propostas curriculares e na prática de uma Escola Família Agrícola no norte do estado do Espírito Santo. A metodologia adotada atribui à pesquisa um caráter qualitativo do tipo etnográfico utilizando-se de três procedimentos para a obtenção de dados: observação participante, análise de documentos e entrevista semiestruturada. Os documentos analisados foram Projeto Político Pedagógico, o Planejamento de Atividades Anual e o Plano de Ensino da Escola Família Agrícola. As entrevistas foram realizadas com 11 estudantes da $3^{a}$ e $4^{a}$ série do ensino médio/técnicoprofissionalizante. Os resultados apontam que, dentro das propostas curriculares da Escola Família Agrícola, a Educação Ambiental se apresenta de forma indissociável das questões educacionais e cotidianas dos estudantes do campo. A temática ambiental é trabalhada dentro das diversas áreas de conhecimento escolar, disciplinas técnicas e em forma de projetos, feitas através de reflexões complexas sobre o contexto ambiental, social e político enfatizando sempre as consequências que a ação do homem gera sobre a terra no município, região e mundo. Deste modo, conclui-se que a Educação Ambiental encontra-se diluída nas propostas curriculares e na prática pedagógica da Escola Família Agrícola no norte do Espírito Santo.

Palavras-chave: Ensino em alternância. Educação Ambiental. Currículo e prática escolar.

Abstract: This research investigated how Environmental Education is present in the curricular proposals and practice of a Agricultural Family School in the north of the state of Espírito Santo. The adopted methodology attributes to the research a qualitative character of the ethnographic type using three procedures for obtaining data: participant observation, document analysis and semi-structured interview. The documents analyzed were the Pedagogical Political Project, the Annual Activity Planning and the Agricultural Family School Teaching Plan. The interviews were conducted with 11 students from the 3rd and 4th grades of high school / technical-professional. The results show that, within the curricular proposals of the Agricultural Family School, the Environmental Education is presented in an inseparable way from the educational and daily issues of the students in the field. The environmental theme is worked within the diverse areas of school knowledge, technical disciplines and in the form of projects, made through complex reflections on the environmental, social and political context, always emphasizing the consequences that human action generates on the land in the municipality, region and world. Thus, it is concluded that the Environmental Education is diluted in the curricular proposals and in the pedagogical practice of Agricultural Family School in the north of Espírito Santo.

Keywords: Alternating teaching. Environmental Education. School curriculum and practice. 


\section{Introdução}

$\mathrm{Na}$ Pedagogia Libertadora de Paulo Freire a educação atua na conscientização das pessoas por meio do trabalho educativo relacionado às questões sociopolíticas (SAVIANI, 2005). Para isso, necessita-se de um ensino centrado na análise de problemas e realidades do meio socioeconômico e cultural, da comunidade local, com seus recursos e necessidades, tendo em vista a ação coletiva frente a esses problemas e realidades (LIBÂNEO, 1991).

Os princípios da pedagogia Freireana vão integrando, gradativamente, a concepção e a prática sociopedagógica das Escolas do Campo, atuando em defesa de uma educação que assuma seu papel social, contemplando os ideais e necessidades do povo camponês. A Escola do Campo nasce e se desenvolve no bojo do movimento da Educação do Campo, tendo como base as experiências de formação humana no contexto de luta dos movimentos sociais por terra e por uma educação pensada para o campo e pelos povos do campo (MOLINA, SÁ, 2012).

Para Caldart (2000) a Escola do Campo não é um tipo diferente de escola, mas apresenta uma identidade própria que reconhece e ajuda no fortalecimento dos povos do campo como sujeitos sociais, que também podem ajudar no processo de humanização do conjunto da sociedade, com suas lutas, sua história, seu trabalho, seus saberes, sua cultura. Os princípios pedagógicos da Educação do Campo elucidam a construção de uma escola onde os valores políticos, sociais, históricos e culturais estejam refletidos no currículo de maneira articulada com o projeto de desenvolvimento humano do educando. Sacristán (2000) aponta que o currículo é uma característica essencial, pois expressa as finalidades da educação e, portanto, é necessário que ele esteja regulamentado de acordo com a realidade escolar. Segundo Silva (2005), na escola isso não implica apenas "pelo conteúdo explícito no currículo, mas no seu funcionamento, nas relações sociais do local de trabalho". Melo, Lima e Costa (2014, p. 178) apontam que o currículo das escolas do campo apresentam

[...] a necessidade de que este possa ser construído a partir da seleção de conhecimentos relevantes, que incentivem mudanças individuais e sociais. Tal processo implica no diálogo 
dos conhecimentos escolares como outros saberes socialmente construídos como é o caso dos saberes da cultura camponesa.

Deste modo, a organização curricular na Pedagogia da Alternância é articulada em forma de rede que, de modo geral, referem-se aos princípios formativos de um ensino que associe experiência à prática e que se baseie em uma ação cooperativa, e o Tema Gerador1 (TG), sistematizado por Paulo Freire (1987), é de onde parte a motivação para a investigação. A própria organização dos Temas Geradores nos anos/períodos reflete um processo de evolução que atende o perfil do ciclo da formação.

Dentro das propostas curriculares da educação básica, a Educação Ambiental (EA) tem sido um sistema mediador entre as esferas educacionais e ambientais através das reflexões voltadas para o âmbito socioambiental. No currículo escolar, a temática ambiental está instituída pelo Ministério da Educação (MEC) como um tema transversal através dos Parâmetros Curriculares Nacionais (PNC) (BRASIL, 1997), percorrendo e se diluindo por todas as disciplinas curriculares de modo a promover diálogos e reflexão crítica. Considera-se, neste caso, que o espaço escolar constitui um campo de possibilidades a ser construído a partir da articulação das propostas curriculares voltadas para a discussão da EA com a Educação do Campo.

Deste modo, nesta pesquisa, buscou-se investigar como a Educação Ambiental está presente nas propostas curriculares e na prática da Escola Família Agrícola de Jaguaré, no estado do Espírito Santo. É importante entendermos também como a Pedagogia da Alternância influencia a relação dos estudantes do campo com a natureza, com o meio em que vivem e uns com os outros, analisando se suas percepções e práticas correspondem a uma abordagem crítica e emancipatória capaz de gerar a transformação social.

\footnotetext{
1 Estas palavras são chamadas geradoras porque, através da combinação de seus elementos básicos, proporcionam a formação de outras. Como palavras do universo vocabular do alfabetizando, são significações constituídas ou re-constituídas em comportamentos seus, que configuram situações existenciais ou, dentro delas, se configuram. Tais significações são plasticamente codificadas em quadros, slides, filminas, etc., representativos das respectivas situações, que, da experiência vivida do alfabetizando, passam para o mundo dos objetos. O alfabetizando ganha distância para ver sua experiência: "ad-mirar". Nesse instante, começa a descodificar (FREIRE, 1987, p. 6).
} 


\section{O campo como espaço de formação}

Até as primeiras décadas do século $X X$ a educação era privilégio de poucos no Brasil, sobretudo, no meio rural. Ela foi estabelecida tardiamente, não sendo sequer mencionada nos textos constitucionais até 1891 (BRASIL, 2002). Apenas no final dos anos 1950 e início dos anos 1960 houve o início de um movimento que podemos considerar como o precursor do que conhecemos hoje como Educação do Campo e se refere ao Movimento de Educação Popular. Este movimento de cunho pedagógico e político teve como um de seus principais disseminadores, no Brasil, Paulo Freire, voltado às massas populares em um trabalho de conscientização e politização da educação, mais especificamente à alfabetização de adultos, mas logo foi interrompida pelo golpe militar de 1964, mantendo-se silenciado por mais de 20 anos. Porém, alguns focos foram mantidos por meio dos movimentos progressistas da Igreja Católica, destacando-se três espaços de resistência: as Comunidades Eclesiais de Base (CEBs) e a Comissão Pastoral da Terra (CPT); a Confederação Nacional dos Trabalhadores da Agricultura (Contag) e; a Pedagogia da Alternância, que teve início no Espírito Santo, em 1968 (FREITAS, 2011, p. 38).

Após a mudança do regime político ditatorial, na segunda metade dos anos de 1980, reiniciaram-se debates sobre questões voltadas à educação popular servindo também como suporte para reivindicação de diversos movimentos sociais. Neste cenário de mudanças, a educação voltada aos povos do Campo volta a ganhar força, impulsionado pela luta dos movimentos sociais organizados que trabalhavam em prol da formação política de lideranças no cenário campesino, reivindicando os direitos no acesso à terra, saúde, educação, moradia, dentre outras (MELO, LIMA, COSTA, 2014). A resistência, a luta pela construção do território camponês e emancipação dos trabalhadores do campo foram primordiais para a criação de uma nova concepção de educação, Educação do Campo, pois concebe o campo como um espaço rico, distinto e produtor de cultura (op. cit., 2014). Sobre Educação do Campo Caldart (2008, p. 71) diz:

Educação do Campo nasceu como mobilização/pressão de movimentos sociais por uma política educacional para 
comunidades camponesas: nasceu da combinação das lutas dos sem terra pela implantação de escolas públicas nas áreas de reforma agrária com as lutas de resistência de inúmeras organizações e comunidades camponesas para não perder suas escolas ou as verem nucleadas, suas experiências de educação, suas comunidades, seu território, sua identidade.

A Educação do Campo tem sido um desafio no Brasil por se tratar de uma educação que atende a comunidades com características particulares atuando como projeto contra hegemônico. Essas raízes são sustentadas nas teorias de Paulo Freire, por exemplo, que denuncia e condena a 'educação bancária' descrita em sua obra Pedagogia do Oprimido (FREIRE, 1987) e integra pouco a pouco a concepção e a prática sociopedagógica das Escolas do Campo encorajando os povos do campo a buscarem e lutarem por uma educação justa e não por qualquer educação. Caldart (2012) afirma ainda que a Educação do Campo:

Constitui-se como luta social pelo acesso dos trabalhadores do campo à educação (e não qualquer educação) feita por eles mesmos e não apenas em seu nome. A Educação do Campo não é para nem apenas com, mas sim, dos camponeses, expressão legítima de uma pedagogia do oprimido (CALDART, 2012, p. 261).

A realidade do campo é heterogênea, e, portanto, a educação deve ser articulada às demandas e especificidades de cada território, de cada localidade, de cada comunidade (BRASIL, 2007), ou seja, é necessária a defesa de que as Escolas do Campo tenham uma educação específica para seu público, diferenciada e baseada em seu contexto, voltada aos interesses e às suas necessidades.

\section{Educação ambiental na formação curricular da escola do campo}

Não é possível pensar/fazer a educação sem considerar os sujeitos concretos e os processos formadores que os constituem como seres humanos desde a práxis social. No que se refere à questão curricular, é importante compreender as relações de poder que envolvem a construção do currículo. Para Moreira e Silva (1994), o currículo não é um elemento neutro de transmissão desinteressada do conhecimento social, estando a ele implicado relações de 
poder, transmissão de visões sociais particulares e interessadas, a produção de identidades individuais e sociais particulares. Para Lima (2013) o processo de construção e articulação curricular deve estar para além da dinâmica de seleção e organização de conteúdos, mas voltado principalmente para redefinição do papel da escola. Além disso, Santos (2009, p. 13-14) afirma que "os conteúdos curriculares devem permitir que os alunos desenvolvam sua capacidade de argumentação, de questionamento, de crítica e sua capacidade de formular propostas de solução para problemas detectados".

Deste modo, os saberes e conteúdos orientados no currículo das Escolas do Campo, além de terem uma relação direta com as vivências e as experiências dos jovens, devem estimular o desenvolvimento de competências e habilidades voltadas para o desenvolvimento das atividades sociais, culturais e produtivas no meio rural (LIMA, 2013). O autor aponta ainda que os currículos das escolas do campo devem integrar os conhecimentos científicos e os saberes populares, buscando a troca entre experiências educativas escolares com as práticas socioeducativas vivenciadas pelos alunos. No processo de construção do currículo é importante considerar as especificidades dos sujeitos do campo, compreendendo-os como plurais. Ou seja,

O campo tem diferentes sujeitos. São pequenos agricultores, quilombolas, povos indígenas, pescadores, camponeses, assentados, reassentados, ribeirinhos, povos da floresta, caipiras, lavradores, roceiros, sem-terra, agregados, caboclos, meeiros, boia-fria, e outros grupos mais. Entre estes há os que estão ligados a alguma forma de organização popular, outros não; há ainda as diferenças de gênero, de etnia, de religião, de geração; são diferentes jeitos de produzir e de viver; diferentes modos de olhar o mundo, de conhecer a realidade e de resolver os problemas; diferentes jeitos de fazer a própria resistência no campo; diferentes lutas (CALDART, 2002, p.21).

Apesar da grande heterogeneidade dos povos do campo, a questão ambiental é comum a todos eles, pois trabalham e sobrevivem diretamente da terra e dos produtos extraídos dela. Deste modo, discutir EA de forma crítica se torna essencial dentro das escolas do campo.

A EA, em sua trajetória de construção teórico-metodológica, é demarcada por uma disputa na busca da garantia da hegemonia de posicionamentos nas instâncias de atuação institucional, acadêmica e social (ROSA, 2015). Segundo 
Loureiro (2006), a princípio, foi formado dois grandes grupos políticopedagógicos dentro da EA que se destacaram e buscaram a predominância no contexto das propostas teóricas e políticas. Pela sistematização feita por Lima (2002) e de elementos feitos por Loureiro (2003 e 2004), pode-se assim classificar os dois blocos em suas ênfases: conservador ou comportamentalista e transformador, crítico ou emancipatório. Cada um apresenta características próprias por terem sido influenciados por diferentes concepções pedagógicas, onde a maneira de ver e entender a Educação e seu papel social é divergente.

Em uma perspectiva que haja o envolvimento político e a busca por mudança social, nasce uma EA comprometida com questões socioambientais, sendo chamada de Educação Ambiental Crítica (GUIMARÃES, 2004), Transformadora (LOUREIRO, 2004) e Emancipatória (LIMA, 2004; QUINTAS, 2004). Essa EA aproxima-se em relação às concepções de Educação do Campo na medida em que se identificam a existência de elementos comuns entre tais concepções.

A Educação do Campo e a Pedagogia do Movimento, tendo como base teórica a dialética de Marx, entende que a relação entre o homem e a terra (natureza) é mediada pelo trabalho. É quando trabalha a terra que o homem modifica a natureza, se funde e se confunde com ela. É por isso que a ideia de sustentabilidade do campo é um dos pilares da Educação do Campo e temas como Agroecologia permeiam seu currículo. Contudo, a EA como integrante curricular necessita superar a fragmentação e compartimentalização dos saberes disciplinares estabelecidos (ROSA, 2015).

\section{Pressupostos metodológicos}

Este trabalho apresenta caráter qualitativo (MINAYO, 2008) e quanto ao método de coleta de dados adotado, a pesquisa se configura como do tipo etnográfica (ANDRÉ, 1995).

A pesquisa ocorreu entre abril a dezembro de 2016, realizada na Escola Família Agrícola (EFA) de Jaguaré localizada no município de Jaguaré, norte do estado do Espírito Santo - 202km da capital Vitória. A EFA de Jaguaré adota a 
Pedagogia da Alternância e segue as orientações da RACEFFAES ${ }^{2}-$ MEPES $^{3}$, da qual recebe toda a supervisão técnica e pedagógica, seguindo o modelo de Educação Profissional Técnica Integrada ao Ensino Médio com Habilitação em Agropecuária - Eixo Tecnológico: Recursos Naturais - Habilitação: Agropecuária.

Para a obtenção dos dados, foram realizadas observação participante, entrevista intensiva e a análise de documentos. Durante a permanência na escola, as observações e diálogos informais que ocorriam eram anotados em um diário de bordo para que pudessem ser analisados posteriormente. Os documentos da EFA de Jaguaré analisados foram o Projeto Político Pedagógico (PPP), o Planejamento de Atividades anual e o Plano de Ensino.

Foram realizadas entrevistas semiestruturadas com 11 estudantes da $3^{a}$ e $4^{a}$ série do ensino médio/técnico-profissionalizante com idades entre 16 a 25 anos, filhos de camponeses que desenvolvem atividades do setor de produção agropecuária, como pequenos proprietários de terras, assentados, meeiros, diaristas ou assalariados agrícolas e também atuantes em atividades do setor terciário como o comércio e prestação de serviços.

As entrevistas foram gravadas frente à autorização dos participantes que assinaram um termo de consentimento de livre esclarecimento. Todos os participantes tiveram suas identidades preservadas sendo identificados com números (estudante 1, estudante 2...). Os áudios foram transcritos e o material foi submetido à análise seguindo o método de Análise de Discurso orientado por Orlandi (2005). Na Análise de Discurso o objetivo é compreender como se dá a produção de sentidos, cabendo ao analista compreender os gestos de interpretação contidos nos domínios dos símbolos e necessitando do artifício da

\footnotetext{
2 A RACEFFAES (Regional das Associações dos Centros Familiares de Formação em Alternância do Espírito Santo) é organizada pelas famílias dos Centros Familiares de Formação em Alternância (CEFFA). A criação da RACEFFAES foi dada pela necessidade de maior articulação entre os CEFFA da região tendo a missão de manter a unidade político-pedagógica com base nos princípios filosóficos e pedagógicos da Pedagogia da Alternância. Atualmente a RACEFFAES congrega 25 Associações e Conselhos de Escola de 12 municípios das regiões do norte e noroeste do Estado do Espírito Santo onde cada sócio participa de forma igualitária no processo de gestão da entidade, garantindo a autonomia e manutenção da organização (RACEFFAES, 2015).

3 O MEPES (Movimento de Educação Promocional do Espírito Santo) é uma organização nãogovernamental (ONG), declarada como pessoa jurídica, sem fins lucrativos (com fins filantrópicos) e de utilidade pública; reconhecido pelo Conselho de Educação do Estado do Espírito; membro fundador da União Nacional das Escolas Famílias (UNEFAB) e da Associação Internacional dos Movimentos Familiares de Formação Rural (AIMFR) (NOSELLA, 1977 e AZEVEDO, 1999 apud RODRIGUES 2008, p. 66).
} 
distinção entre "a inteligibilidade, a interpretação e a compreensão" (MARIANI, 2000).

Após a construção do corpus da pesquisa foram definidas as seguintes estruturas de análise: (1) A EA na organização curricular das Escolas Família Agrícola/RACEFFAES-MEPES, (2) a EA no Plano de Estudo da EFA de Jaguaré e (3) a EA e práticas escolares.

\section{Organização curricular das Escolas Família Agrícola/RACEFFAES-MEPES e possibilidades de diálogos com a EA}

A organização curricular das EFAs do norte do estado do Espírito Santo associadas à RACEFFAES se dá por meio da articulação da Base Nacional Comum Curricular (BNCC) com os respectivos componentes curriculares (disciplina) apresentando suas competências, habilidades e bases tecnológicas e, também, com os Temas Geradores (TGs). Todo o currículo é pensado e organizado respeitando a parte diversificada inerente à vida no campo e em observância às experiências de educação em alternância. Deste modo, os conhecimentos curriculares e técnicos norteados pela BNCC são sempre trabalhados associados às questões comuns à realidade vivenciada no trabalho no campo, à sociedade e ao ambiente, estimulando o senso crítico dos estudantes de forma a proporcionar uma formação integral dos estudantes.

Essa proposta é defendida por Freire (1987) e classificada como educação dialógica, que começa quando o educador se pergunta em torno do que vai dialogar com os educandos. Ou seja, a educação dialógica começa quando o educador reflete sobre quais são os conteúdos e os saberes escolares que devem ser tratados na escola. Os TGs, segundo Oliveira et al. (2017, p. 1415) "destacam a necessidade de atribuir sentido prático aos conceitos científicos na relação teoria e prática de modo que favoreçam a análise de problemas atuais pertinentes da realidade".

O enfoque dos TGs é garantido e firmado no Plano de Estudo 4 (PE) que representa o cerne do movimento da dinâmica da formação em alternância. 0

\footnotetext{
$4 \mathrm{O}$ PE é elaborado pelos próprios professores/monitores associados à RACEFFAES. Um grupo de professores das 29 escolas articuladas se reúne para discutirem os temas que são relevantes aos estudantes do campo de acordo com cada disciplina e que estejam em concordância com os temas geradores e eixos temáticos.
} 
PE dirige-se às questões políticas, econômicas, ambientais e socioculturais e se transforma em um programa de grandes ou pequenos ciclos/períodos, contendo planejamento, execução e avaliação com seus desdobramentos a nível pessoal, das relações sociais e de suas relações com a realidade. O método do PE se estrutura na seguinte dinâmica: mobilização/investigação, problematização, reflexão/generalização e conscientização/ação. Por meio dessa investigação, de sua socialização, problematização e sistematização é que se desenvolvem as demais atividades na sede da escola, sempre no sentido de ampliar, esclarecer, criar novas expectativas e esperanças em relação à vida no campo. Deste modo, a organização curricular favorece o diálogo entre a Educação do Campo e Educação Ambiental uma vez que o homem do campo e sua forma de vida estão diretamente ligados à sua relação com a natureza mediada pelo trabalho.

Todas as áreas do conhecimento e seus respectivos componentes curriculares seguem mesmo TG e, de acordo com a série, os temas de estudo são variados, mas sempre em concordância com a proposta central da Educação do Campo. Temas como o uso e aproveitamento do solo e a distribuição da terra; a saúde das plantações e criações; o clima, a energia e a produção agroecológica; administração do estabelecimento agropecuário e organizações sociais do campo norteiam as discussões realizadas no processo de ensino/aprendizagem.

\section{A Educação Ambiental no Plano de Estudo da EFA de Jaguaré}

Apontam-se, a seguir, os eixos temáticos ${ }^{5}$ e os temas geradores que norteiam as propostas curriculares da EFA de Jaguaré com alguns exemplos de temas de plano de estudo (QUADRO 1). Concomitantemente a essa apresentação, foram analisados os planos de ensino de disciplinas da grade do ensino médio/técnico-profissionalizante da EFA de Jaguaré buscando identificar se/como a EA se encontra disposta nos conteúdos sugeridos.

\footnotetext{
${ }^{5}$ Os eixos temáticos e os temas geradores foram extraídos do PPP da EFA de Jaguaré.
} 
Quadro 1: Organização curricular com eixo temático, temas geradores, propostas de temas para plano de estudo e objetivos a serem contemplados nas disciplinas regulares e técnicas da $1^{a}$ série da EFA de Jaguaré.

\begin{tabular}{|c|c|c|c|}
\hline $1^{\text {a }}$ SÉRIE & $\begin{array}{c}\text { TEMA } \\
\text { GERADOR }\end{array}$ & $\begin{array}{l}\text { TEMAS DO } \\
\text { PLANO DE } \\
\text { ESTUDO }\end{array}$ & OBJETIVOS \\
\hline \multirow{3}{*}{$\begin{array}{c}\text { EIXO } \\
\text { TEMÁTICO: } \\
\text { A relação do } \\
\text { homem com a } \\
\text { natureza pelo } \\
\text { trabalho }\end{array}$} & \multirow[t]{2}{*}{$\begin{array}{c}\text { O Homem e a } \\
\text { Terra }\end{array}$} & $\begin{array}{l}\text { O uso e o } \\
\text { aproveitamento } \\
\text { do solo }\end{array}$ & \multirow{2}{*}{$\begin{array}{l}\text { - Reconhecer a terra como fonte de } \\
\text { luta, resistências e vida da família } \\
\text { camponesa; } \\
\text { - Refletir sobre a necessidade de } \\
\text { conservação da terra e dos recursos } \\
\text { naturais; } \\
\text { - Refletir os conflitos, as } \\
\text { contradições no uso e divisão da } \\
\text { terra [...]; } \\
\text { - Analisar a questão fundiária do } \\
\text { Brasil e sua influência [...]. }\end{array}$} \\
\hline & & $\begin{array}{l}\text { A distribuição da } \\
\text { terra em nossa } \\
\text { região. }\end{array}$ & \\
\hline & A Alimentação & $\begin{array}{l}\text { Alimentação das } \\
\text { plantações e das } \\
\text { criações }\end{array}$ & $\begin{array}{l}\text { - Analisar o fenômeno da } \\
\text { alimentação de forma global [..] } \\
\text { entendendo o meio ambiente de } \\
\text { forma científica para promover seus } \\
\text { equilíbrios ecológicos[...]. } \\
\text { - Refletir e perceber formas } \\
\text { alternativas de produzir e distribuir } \\
\text { alimentos em vista da } \\
\text { sustentabilidade camponesa e } \\
\text { erradicação da fome; } \\
\text { - Conceber formas de alimentação } \\
\text { alternativa para as criações e } \\
\text { plantações. }\end{array}$ \\
\hline
\end{tabular}

Fonte: Projeto Político Pedagógico da EFA de Jaguaré - Adaptado.

Nas $1^{\mathrm{a}}$ e $2^{\mathrm{a}}$ séries, os TGs apresentam caráter científico, criando a possibilidade da confirmação da escolha profissional dos estudantes. Nota-se por essa teia de temas, que os assuntos propostos se complementam e os conteúdos de cada disciplina se associação com a questão ambiental. Disciplinas das áreas de humanas, linguagens, naturais e matemática buscam, dentro de seus elementos específicos, trabalhar sempre em diálogo com as percepções socioambientais.

No plano de ensino da $1^{\text {a }}$ série na disciplina de Matemática, por exemplo, seguindo o tema gerador - O Homem e a Terra - e o tema de Plano de Estudo $O$ uso e o aproveitamento do solo-, trabalham-se os conteúdos: sistema métrico decimal; medidas de comprimento; medidas de superfície das figuras planas, unidades de medidas (medidas de área, medidas agrárias). A partir desses conteúdos a motivação é aprender a dimensionar as áreas da unidade produtiva 
para um melhor aproveitamento do espaço agrícola. Dentro dessa discussão a presença da EA se dá ao serem discutidas questões de uso do espaço natural e as necessárias abordagens de questões ambientais que estão envolvidas sobre essa ação.

Outra disciplina analisada foi a Filosofia que, sob esse mesmo tema gerador e plano de estudo, os conteúdos trabalhados foram: concepção do homem em cada período da história; o homem, um ser com destino - de uma natureza própria e um ser social; dentre outros. A EA permeia na Filosofia de forma a possibilitar a compreensão das diversas concepções da relação e transcendência entre homem-natureza de acordo com o pensamento predominante em cada época. Segundo Farias (2008), o estudo da Filosofia da crise socioambiental possibilita a problematização das estruturas que configuram a nossa representação da natureza, pois, através dela, torna-se o pensamento ecológico mais crítico e, portanto, mais efetivo do ponto de vista de seu alcance social.

Analisando as propostas do plano de estudo para a $2^{\mathrm{a}}$ série, observa-se que a EA em suas várias vertentes (social, política, econômica, histórica) em conformidade com os temas geradores (QUADRO 2).

Quadro 2: Organização curricular com eixo temático, temas geradores, propostas de temas para plano de estudo e objetivos a serem contemplados nas disciplinas regulares e técnicas da $2^{a}$ série da EFA de Jaguaré.

\begin{tabular}{|c|c|c|c|}
\hline $2^{\mathrm{a}}$ SÉRIE & $\begin{array}{c}\text { TEMA } \\
\text { GERADOR }\end{array}$ & $\begin{array}{l}\text { TEMAS DO } \\
\text { PLANO DE } \\
\text { ESTUDO }\end{array}$ & OBJETIVOS \\
\hline \multirow{2}{*}{$\begin{array}{l}\text { EIXO TEMÁTICO: } \\
\text { A vida se } \\
\text { reproduz em } \\
\text { movimento }\end{array}$} & A Saúde & $\begin{array}{l}\text { A Saúde das } \\
\text { Plantações e } \\
\text { das Criações. }\end{array}$ & $\begin{array}{l}\text { - Analisar as relações existentes } \\
\text { entre saúde, alimentação e meio } \\
\text { ambiente em vários níveis (social, } \\
\text { político, econômico e agrícola); } \\
\text { - Compreender as contradições } \\
\text { entre as formas convencionais e } \\
\text { alternativas de prevenir e } \\
\text { controlar os problemas de saúde, } \\
\text { tanto no ser humano, nas } \\
\text { plantações e criações. }\end{array}$ \\
\hline & A Reprodução & $\begin{array}{l}\text { A Reprodução } \\
\text { das Plantações } \\
\text { e das Criações. }\end{array}$ & $\begin{array}{l}\text { - Compreender como o fenômeno } \\
\text { da reprodução envolve demandas } \\
\text { políticas e tecnológicas, tanto em } \\
\text { torno da sociedade humana como } \\
\text { na produção agropecuária. } \\
\text { - Conhecer meios de reprodução } \\
\text { em vista do melhoramento } \\
\text { genético das plantações e } \\
\text { criações; }\end{array}$ \\
\hline
\end{tabular}




\begin{tabular}{|l|l|l|}
\hline & & $\begin{array}{l}\text {-Compreender a transformação } \\
\text { biológica do ser humano, } \\
\text { buscando refletir os tabus e } \\
\text { preconceitos sobre a } \\
\text { sexualidade. }\end{array}$ \\
\hline
\end{tabular}

Fonte: Projeto Político Pedagógico da EFA de Jaguaré - Adaptado

$\mathrm{Na}$ disciplina de Língua Portuguesa da $2^{\mathrm{a}}$ série, por exemplo, são trabalhados os assuntos: morfologia - estrutura e formação das palavras; ortografia; morfologia substantivo/adjetivo/artigo/numeral/verbo/pronome; as manifestações literárias humanas: humanismo/renascimento integrada com história (renascimento, reformas e revoluções); dentre outros. A EA, através da compreensão da linguagem literária, permeia como manifestação cultural e das experiências humanas transmitidas na forma de sentir, pensar e agir na vida social. Segundo Marcuschi (2004), os gêneros textuais, como práticas sociohistóricas, se compõem como atividades para atuar sobre o mundo e dizer o mundo, constituindo-o de algum modo. O estudo humanístico possibilita que o educando compreenda as relações entre homem-natureza através da arte, do uso da terra, das relações interpessoais e culturais em cada momento histórico, sendo levados a uma leitura de mundo, dos fatos ocorridos e também de possibilidades futuras para essa relação.

Nas $3^{\mathrm{a}}$ e $4^{\mathrm{a}}$ séries, os temas geradores assumem um caráter técnicosociopolítico fomentando a consolidação da base profissional do jovem camponês. O quadro 3 apresenta as propostas temáticas da $3^{a}$ série.

Quadro 3: Organização curricular com eixo temático, tema gerador, propostas de temas para plano de estudo e objetivos a serem contemplados nas disciplinas regulares e técnicas da $3^{a}$ série da EFA de Jaguaré.

\begin{tabular}{|c|c|c|c|}
\hline $3^{a}$ SÉRIE & $\begin{array}{c}\text { TEMA } \\
\text { GERADOR }\end{array}$ & $\begin{array}{c}\text { TEMAS DO } \\
\text { PLANO DE } \\
\text { ESTUDO } \\
\end{array}$ & OBJETIVOS \\
\hline $\begin{array}{l}\text { EIXO TEMÁTICO: } \\
\text { Por um } \\
\text { desenvolvimento } \\
\text { sustentável e } \\
\text { equilibrado do } \\
\text { campo }\end{array}$ & Agroecologia & $\begin{array}{l}\text { O clima e a } \\
\text { energia na } \\
\text { produção } \\
\text { agroecológica }\end{array}$ & $\begin{array}{l}\text { - Despertar na realidade agropecuária } \\
\text { da região a visão agroecológica como } \\
\text { opção e alternativa viável para o } \\
\text { campo no âmbito ecológico, social, } \\
\text { político e econômico. } \\
\text { - Resgatar e/ou conceber valores da } \\
\text { ruralidade para os habitantes e } \\
\text { trabalhadores do campo [...]. } \\
\text { - Incentivar a diversificação } \\
\text { agropecuária como meio de motivar a } \\
\text { agricultura camponesa. }\end{array}$ \\
\hline
\end{tabular}




\begin{tabular}{|l|l|l|}
\hline & Diversificação & - Estudar as funções que a diversidade \\
Agropecuária & $\begin{array}{l}\text { de cultivo exerce na sociedade [...]. } \\
\text { - Analisar as relações de trabalho, a } \\
\text { evolução das técnicas de cultivo e a } \\
\text { sustentabilidade da agricultura } \\
\text { camponesa, tendo em vista a } \\
\text { soberania e qualidade alimentar em } \\
\text { nível local, regional, nacional e e } \\
\text { internacional. }\end{array}$ \\
\hline
\end{tabular}

Fonte: Projeto Político Pedagógico da EFA de Jaguaré - Adaptado

Deste modo, através dos estudos físicos, é possível discutir EA a partir da identificação dos fenômenos climáticos e a utilização das diversas formas de energia no campo. Os fatores climáticos e as fontes de energia são elementos fundamentais para o desenvolvimento das atividades biológicas, deste modo, a física, associada às demandas do campo, oferece uma importante contribuição à formação dos jovens camponeses. Assis Junior et al. (2008, p. 11) associam o ensino dos conceitos de Física aos aspectos ambientais de forma a "viabilizar que eles atuem em seu cotidiano de forma crítica e consciente, agindo enquanto elementos propagadores da educação ambiental, a fim de contribuírem para a preservação do meio ambiente".

Nas disciplinas específicas do curso técnico as questões ambientais se encontram ainda mais presentes. Os conteúdos se referem diretamente ao ambiente, sua influência sobre as produções e o manejo deste pelo homem, sendo listados: introdução e conceituação de agroecologia e sua relação com o clima; o ambiente sentido pelas plantas; as exigências e variações climáticas e o comportamento das plantas; as variações climáticas e os impactos na agricultura; capacidade de uso do solo (recuperação); tecnologias apropriadas à conservação de água no solo (consórcio e arranjo produtivo, sombreamento/arborização, cultivo mínimo, manejo com as ervas espontâneas, e calendário agrícola); conservação da natureza e áreas degradadas. Essas discussões fortalecem ainda mais a conscientização da importância da EA na vida do campo, formando jovens com preocupações que vão além do viés puramente econômico.

O quadro 4, a seguir, apresenta as propostas temáticas da $4^{\mathrm{a}}$ série: 
Quadro 4: Organização curricular com eixo temático, temas geradores, propostas de temas para plano de estudo e objetivos a serem contemplados nas disciplinas regulares e técnicas da $4^{a}$ série da EFA de Jaguaré.

\begin{tabular}{|c|c|c|c|}
\hline $4^{a}$ SÉRIE & $\begin{array}{c}\text { TEMA } \\
\text { GERADOR }\end{array}$ & $\begin{array}{l}\text { TEMAS DO } \\
\text { PLANO DE } \\
\text { ESTUDO }\end{array}$ & OBJETIVOS \\
\hline \multirow[t]{2}{*}{$\begin{array}{l}\text { EIXO TEMÁTICO: } \\
\text { O campo espaço } \\
\text { de vida digna }\end{array}$} & \multirow[t]{2}{*}{$\begin{array}{c}\text { Administração } \\
\text { Rural }\end{array}$} & $\begin{array}{l}\text { Administração do } \\
\text { estabelecimento } \\
\text { agropecuário com } \\
\text { Bovinocultura } \\
\text { Leiteira }\end{array}$ & \multirow{2}{*}{$\begin{array}{l}\text { - Compreender a importância da } \\
\text { administração rural como fator } \\
\text { de sustentabilidade da } \\
\text { produtividade agrícola, } \\
\text { conhecendo as teorias da } \\
\text { gerência. } \\
\text { - Estimular a organização socia } \\
\text { camponesa como forma de } \\
\text { superar o individualismo, } \\
\text { melhorar a produção e } \\
\text { manifestar a cultura como } \\
\text { elementos básicos da qualidade } \\
\text { da vida no campo. } \\
\text { - Compreender a importância da } \\
\text { bovinocultura como um dos } \\
\text { elementos de diversificação no } \\
\text { sentido de desmistificar os } \\
\text { modelos monocultores } \\
\text { extensivos da região e motivar } \\
\text { para o manejo alternativo do } \\
\text { café para a economia das } \\
\text { famílias do campo. }\end{array}$} \\
\hline & & $\begin{array}{l}\text { As organizações } \\
\text { Sociais do } \\
\text { Campo }\end{array}$ & \\
\hline
\end{tabular}

Fonte: Projeto Político Pedagógico da EFA de Jaguaré - Adaptado

Ao chegarem nesta série, os estudantes encontram-se apropriados de saberes técnicos, econômicos e socioambientais e, neste momento, as apresentações dos temas remetem a um cuidado ainda maior do viés social reforçando o estabelecimento de uma visão ambiental complexa e atuante. Paula e Henrique (2016, p. 90) apontam que essa perspectiva de formação humana crítico-reflexiva tem estreita relação com a Educação Ambiental, uma vez que "a construção de alternativas para o meio ambiente e sua sustentabilidade passa por compreender os problemas, as crises e os potenciais de uma sociedade a partir de uma reflexão crítica".

Na disciplina técnica de Irrigação e Drenagem são tratados assuntos, como: características dos emissores (aspersores, gotejadores, micro aspersores); definição e cálculos de hora trabalho, tempo por posição, posição por dia; dimensionamento das tubulações, conexões e acessórios; vazão necessária; potência da bomba, cálculo e dimensionamento; dentre outras. As finalidades desses ensinamentos são para um melhor dimensionamento de 
irrigação e fazer economia de tempo, água e mão de obra, conhecer e relacionar os sistemas de irrigação de acordo com a realidade da família e dominar as técnicas de dimensionamento de sistemas de irrigação adequadas à realidade de cada estabelecimento.

Nesta perspectiva, os estudantes adquirem domínio sobre diferentes técnicas e aprendem quais são mais viáveis ou não, respeitando os limites ambientais ao passo que proporcionam o bem-estar ao homem e sua família. Contudo, Layrargues (2006, p. 6) afirma que apesar dos esforços da EA direcionados para a dimensão ética do relacionamento do homem com a natureza, onde se pretende torná-la um Bem em si, "ela continua sendo uma Mercadoria (seja na forma de produtos ou serviços ecológicos), com um valor de troca". O autor discute a questão da proteção da água pura, como um exemplo de um Bem em si, apontando como sua distribuição e utilização se distanciam da maneira que se compreende como adequada à questão ambiental, afastando-se, também, das discussão e devidas interpretações de seus significados ideológicos.

Outro aspecto importante na discussão sobre o 'agente causador da crise ambiental', paralelo à escassez absoluta da água, é a tentativa de generalização da "humanidade" enquanto responsável por ela. Layrargues (2006), sobre essa ótica, aponta que este é um artifício ideológico que camufla a existência de sujeitos sociais específicos.

Assim, a repartição dos benefícios (a geração de riqueza) e prejuízos (a geração de danos e riscos ambientais) do acesso, apropriação, uso e abuso da Natureza e recursos ambientais em geral, através do trabalho na sociedade capitalista, é sempre mediada por relações produtivas e mercantis, e como tal, está sujeita à assimetria do poder nas relações sociais, expondo ao risco ambiental os grupos sociais vulneráveis às condições ambientais em processo de degradação (como as populações marginalizadas nos centros urbanos), ou dependentes de recursos naturais em processo de exaustão (como as populações indígenas e extrativistas) agravando a já delicada situação de opressão social e exploração econômica a que tais grupos sociais são impostos pelos setores dirigentes (LAYRARGUES, 2006, p. 7). 
A questão ambiental emerge, nessa perspectiva, como uma questão eminentemente de justiça distributiva, tornando a gestão dos conflitos socioambientais democrática e participativa. A EA é capaz de gerar mudanças individuais e coletivas, locais e globais que provocam uma abordagem colaborativa e crítica na busca da resolução dos problemas (LOUREIRO, 2004).

Quanto à articulação curricular e a práxis docente, Freire (1994) reforça a necessidade de aproveitar a experiência de vida dos alunos para o estabelecimento de uma relação entre a questão ambiental e a educação, a política, a pobreza, a saúde e a ética, para discutir problemas sociais como a poluição, os baixos níveis de bem-estar das pessoas, saneamento básico, os lixões que conferem risco à saúde das populações.

\section{Educação Ambiental e práticas escolares}

Com base na análise dos PEs, dos TGs e propostas disciplinares, a EA foi identificada no currículo da EFA. Além disso, a EA foi percebida na prática por meio da execução de atividades/projetos/reflexões coletivas relacionadas à temática. Nas entrevistas realizadas com os estudantes, buscou-se identificar quais atividades/projetos a EFA de Jaguaré desenvolve na área ambiental e como estes são percebidos por eles.

Nós desenvolvemos bastantes projetos, um deles é o de EA que nós estamos fazendo esse trimestre que aborda as causas da seca e as atitudes que o ser humano está tendo com o meio ambiente. Engloba tudo, reflorestamento, até mesmo para conscientizar as pessoas que sem árvore o ambiente não consegue viver. (Estudante 4)

Aqui na escola tem um projeto realizado toda quinta-feira sobre meio ambiente. A gente fala como está a nossa comunidade e, como nesse período está abrangendo mais a seca, a gente tem tipo que apontar sugestões para melhorar. (Estudante 9)

Projeto de EA com maior relevância, nesse período agora, é o projeto de meio ambiente que foi iniciado. A gente tem mais um conhecimento teórico do que é o meio ambiente, as consequências dos efeitos que o homem acaba causando e tentando levar na prática [...]. (Estudante 10)

Com base nos discursos dos estudantes e pela análise do plano de atividades anuais propostas pela EFA, a realização de projetos é uma prática 
comum e fundamental no processo educativo da escola. Como aponta o discurso do estudante 9, o cerne das discussões é o estudo da realidade em que estão inseridos, de suas comunidades, proporcionando um momento de apontamentos de sugestões para a resolução dos problemas identificados.

A presença da temática 'seca' nas falas dos estudantes se deu devido à crise hídrica que o estado do Espírito Santo sofreu entre os anos de 2014 a 2016. Segundo estudos do Incaper $^{6}$ (2016), o estado apresentou saldo negativo para a precipitação pluviométrica no ano hidrológico 2014-2015 com baixa recarga do lençol freático, provocando sérias consequências para o ano hidrológico 20152016. Em uma publicação feita pelo portal G1 (ARPINI, 2016), esse período de estiagem foi o pior dos últimos 80 anos e acarretou em muitos prejuízos no consumo humano e no setor econômico, em especial, no campo agrícola.

Jaguaré, município em que foi realizada a pesquisa - se destaca no campo agrícola estadual, tendo como base da economia local a cafeicultura no cultivo do Café Conilon (Coffea canephora), seguido de feijão, milho, mamão e pimenta-do-reino (IBGE, 2017) - também sofreu os danos causados pela estiagem no período supracitado. Deste modo, o trabalho da EFA junto aos alunos e comunidade foi propor discussões que promovessem uma análise crítica sobre o contexto enfrentado gerando a consciência socioambiental na busca de alternativas para minimizar os impactos causados pela crise hídrica e, consecutivamente, econômica na região.

No período da pesquisa, iniciava na EFA o projeto intitulado "Projeto de Reciclagem como proposta para a Educação Ambiental" tendo como objetivos: a) Sensibilizar os estudantes a terem um olhar sobre o meio ambiente como "um todo" a fim de perceberem não apenas a natureza como ambiente, mas todos os espaços, e dessa forma o estudante ser protagonista no sentido de agir localmente e pensando de forma global; b) Trazer para o debate a problemática da escassez de água, bem como os conflitos gerados em vista do manejo do uso, sobretudo no meio rural; c) Contribuir com os estudantes para que eles

\footnotetext{
${ }^{6}$ Instituto Capixaba de Pesquisa, Assistência Técnica e Extensão Rural (Incaper) autarquia vinculada à Secretaria de Estado da Agricultura, Abastecimento, Aquicultura e Pesca (Seag), é responsável pelos serviços de pesquisa aplicada, assistência técnica e extensão rural no âmbito do Estado do Espírito Santo.
} 
compreendam a importância das práticas para o desenvolvimento sustentável; d) Produzir com os estudantes um documento com encaminhamentos que apontem possíveis soluções para o problema do lixo no ambiente educativo da EFA, a fim de subsidiar as discussões na vida de grupo via Associação de Estudantes.

O projeto foi realizado em forma de oficinas abrangendo conteúdos, problemas e atividades de reflexão não se limitando à ideia reducionista de 'reciclagem e coleta seletiva' como aponta Layrargues (2002) em sua discussão sobre o significado ideológico da reciclagem e suas implicações para a educação ambiental. Layrargues (2006) discute a responsabilidade social da EA como propiciadora do desenvolvimento de uma consciência ecológica no educando, com um trabalho que articula o planejamento político-pedagógico de modo a enfrentar também a padronização cultural, a exclusão social, a concentração de renda, a apatia política, a alienação ideológica; questões estas que estão muito além da degradação do ambiente. Deste modo, a EA no currículo escolar enfrenta o desafio da complexidade, uma vez que se discutem os problemas ambientais em decorrência de práticas sociais, dentro de contextos políticos, econômicos e culturais específicos (não generalista) e o enfrentamento de suas consequências.

Outro trabalho identificado na EFA foi o "Arborizando a escola".

O projeto de arborização da escola onde cada estudante plantou uma árvore de espécie diferente. Foram já 150 árvores plantadas, uma por cada estudante e cada um vai cuidar até sair da escola. Elas foram plantadas ao redor e no pátio da escola, aí cada um tem a sua árvore demarcada; cada um cuida da sua, dos locais. Na hora do lanche, molha e quando a pessoa sair da escola vai deixar para outra [...]. (Estudante 1)

Este projeto contribuiu no processo de formação de conceitos em relação aos cuidados da preservação e manutenção ambiental. Do mesmo modo, o trabalho foi realizado seguindo etapas que compreendiam abordagem teórica, reflexiva e prática não se limitando à ideia ecológica e naturalista de meio ambiente.

Os estudantes relataram suas experiências durante o plantio e cuidado de suas árvores, e como essa rotina os proporcionou um novo olhar sobre o cuidado 
e manutenção da vida. Nesta atividade, inúmeras mudas foram disponibilizadas para o plantio nas propriedades dos estudantes, proporcionando-os uma experiência dialógica familiar. A avaliação geral realizada sobre o projeto mostra que os estudantes se aproximaram mais do ambiente natural, compreendendo a importância de zelar por ele, uma vez que o percebem como "casa", seu local de "habitação" e trabalho, onde ocorrem todas as interações possíveis, sejam elas naturais e sociais. Deste modo, a EA, entendida como uma face da Educação voltada especificamente ao enfrentamento pedagógico da questão ambiental, proporciona a internalização da dimensão ambiental no sistema de ensino, assumindo características abordadas na sociologia da educação, por se tratar de uma modalidade educativa destinada a diluir-se pelos espaços pedagógicos no tecido social, na perspectiva da educação permanente (LAYRARGUES, 2006).

É relevante salientarmos a importância de se atuar com Pedagogia de Projetos. Prado (2005, p. 13) apresenta a discussão de que com esta prática pedagógica "o aluno aprende no processo de produzir, levantar dúvidas, pesquisar e criar relações que incentivam novas buscas, descobertas, compreensões e reconstruções de conhecimento". Deste modo, o professor deixa a posição daquele que ensina por meio da transmissão de informações e passa a criar situações de aprendizagem cabendo ao professor a função de mediador do processo para que o aluno possa encontrar sentido naquilo que está aprendendo a partir das relações criadas nessas situações. A autora nos diz ainda que para realizar essa mediação pedagógica, o professor precisa entender o caminho do educando, assim como seu universo cognitivo e afetivo, sua cultura, história e contexto de vida. No campo, o professor se encontra mergulhado (e se não, em algum momento passará a estar) nas raízes históricosociais de seus educandos o que torna o processo mais fluido e intenso.

Segundo Lima (2013) projetos educativos e projetos de desenvolvimento das comunidades devem estar em sintonia sempre, para que os conhecimentos e saberes produzidos na escola possibilitem que os alunos atuem ativamente nos projetos de transformação social e na produção de novos saberes sociais, culturais e tecnológicos que estão voltados para o desenvolvimento utilizando de 
forma sustentável os potenciais culturais, ambientais, organizativos e produtivos de cada região.

\section{Considerações finais}

Por fim, compreendemos que a EA se encontra articulada dentro das propostas curriculares da escola do campo atuando como um importante instrumento de mediação e formação cidadã dos estudantes, preocupando-se com o contexto ambiental e, consequentemente, o social enfatizando sempre as consequências que a ação do homem gera sobre a terra, no município, região e mundo.

Evidenciou-se com as análises sobre as propostas curriculares da EFA que a EA é indissociável das questões educacionais e cotidianas dos estudantes sendo trabalhada permanentemente dentro das diversas áreas do conhecimento escolar, de modo a ultrapassar os limites do currículo. A EA está diluída dentro da matemática, história, língua portuguesa, física, nos trabalhos de artes e discussões filosóficas. Nas atividades práticas e teóricas das disciplinas técnicas, assim como nos projetos com temáticas ambientais, a EA se materializa e, consolidando-se, é percebida como ferramenta de reflexão sobre as práticas agrícolas e manejo da terra realizados nas propriedades das famílias ou onde trabalham.

Nesta concepção, a Educação Ambiental e a Educação do Campo encontram-se articuladas e ambas lutam por causas em comum, visando o direito à qualidade de vida, de educação dialógica, de promoção da natureza, da questão socioambiental. Educação Ambiental nas Escolas do Campo se volta às questões do ambiente natural, histórico, social, político e cultural, e deste modo, tem a função de contribuir com a formação de sujeitos responsáveis, capazes de refletir e agir sobre a integração dessas vertentes dentro de suas realidades, capazes de cooperar e, acima de tudo, que possuam um compromisso ético e responsável com o meio ambiente.

\section{Referências}

ANDRÉ, M. E. D. A. Etnografia na prática escolar. Campinas: Papirus, 1995. 
ARPINI, N. Seca deixa 20 cidades do ES em situação 'extremamente crítica'. G1, Espírito Santo, 20 set. 2016. Disponível em: http://g1.globo.com/espiritosanto/noticia/2016/09/seca-deixa-20-cidades-do-es-estao-em-situacaoextremamente-critica.html Acesso em: 18 mai. 2020.

ASSIS JUNIOR, A.; ASSIS, A.; CARVALHO, F. L.C. Física e meio ambiente no ensino fundamental: possibilidades, desafios e limitações. In: ENCONTRO DE PESQUISA EM ENSINO DE FÍSICA, 11, Curitiba, 2008. Atas eletrônicas... Curitiba: SBF, 2008. Disponível em: http://www.sbf1.sbfisica.org.br/eventos/epef/xi/sys/resumos/T01253.pdf Acesso: 27 abr 2020.

BRANDÃO, E. C. A educação do campo no Brasil e desenvolvimento da consciência. In: VIII Seminário do Trabalho: Trabalho, Educação e Políticas Sociais no Século XXI, 2012, Marília-SP. VIII Seminário do Trabalho: Trabalho, Educação e Políticas Sociais no Século XXI. Paranavaí-PR: Ronaldo Frutuozo, 2012. v. I. p. 1-11.

BRASIL. Parâmetros curriculares nacionais: meio ambiente, saúde / Secretaria de Educação Fundamental. - Brasília, 1997. 128p.

Diretrizes Operacionais para a educação básica nas escolas do Campo. Resolução CNE/CEB nº I, de 3 de abril de 2002.

. Vamos cuidar do Brasil: conceitos e práticas em educação ambiental na escola - Brasília: Ministério da Educação, Coordenação Geral de Educação Ambiental: Ministério do Meio Ambiente, Departamento de Educação Ambiental: UNESCO, 2007.

CALDART, R. S. Pedagogia do movimento sem-terra. Petrópolis: Vozes, 2000.

. Por uma educação do campo: traços de uma identidade em construção. In: Educação do campo: identidade e políticas públicas- Caderno 4. Brasília: Articulação Nacional "Por Uma Educação Do Campo", 2002. Disponível em: http://www.forumeja.org.br/ec/files/Vol\%204\%20Educa\%C3\%A7\%C3\%A30\%20 B\%C3\%A1sica\%20do\%20Campo.pdf Acesso: 25 mai 2020.

Sobre Educação do Campo. In: SANTOS, Clarice Aparecida dos (Org.). Educação do Campo: campo- políticas públicas - educação. Brasília: INCRA; MDA. $2008 . \quad$ Disponível em: https://www.nead.mda.gov.br>download/por_uma_educacao_do_campo Acesso: 22 mai 2020.

Educação do Campo. In: CALDART, R.S., PEREIRA, I. B., ALENTEJANO, P., FRIGOTTO, G. Dicionário da Educação do Campo. Rio de Janeiro, São Paulo: Escola Politécnica de Saúde Joaquim Venâncio, Expressão Popular, 2012. p. 259-267.

FARIAS, A. B. Filosofia e ecologia - para uma educação ambiental. Congresso Internacional de Filosofia. 2008. Disponível em: 
https://www.ucs.br/ucs/tplCongressoFilosofia/extensao/agenda/eventos/cd 60/c omunicacoes cientificas/apresentacao/papel filosofia/andre.pdf Acesso: 22 mar 2020.

FREIRE, P. Pedagogia do oprimido. 17ª ed. Rio de Janeiro: Paz e Terra, 1987.

Pedagogia da autonomia: saberes necessários à prática educativa. São Paulo: Paz e Terra, 1994.

FREITAS, H. C. Rumos da Educação do Campo. Em Aberto, Brasília, INEP, v. 24, n. 85, p 35-49, abr. 2011.

GUIMARÃES, M. Educação Ambiental Crítica. In: LAYRARGUES, P. P. (coord.). Identidades da Educação Ambiental Brasileira. Brasília: Ministério do Meio Ambiente, 2004.

Instituto Brasileiro de Geografia e Estatística. IBGE - Censo Agropecuário 2017. Resultados definitivos. Rio de Janeiro: IBGE, 2017. Disponível em: https://censoagro2017.ibge.gov.br/templates/censo agro/resultadosagro/agricul tura.html?localidade=32\&tema=76256. Acesso em: 20 mar. 2020.

Instituto Capixaba de Pesquisa, Assistência Técnica e Extensão Rural - Incaper. Estratégias de convivência com a estiagem e gestão dos recursos hídricos no Espírito Santos. Incaper em Revista, Vitória, v. 6 e 7, n. 4, p. 6-25, jan 2015/dez 2016. ISSN 2179-5304. Disponível em: https://biblioteca.incaper.es.gov.br/digital/bitstream/item/2538/1/BRTincaperemrevista-2016.pdf Acesso em: 25 mai 2020.

LAYRARGUES, P. P. Muito além da natureza: educação ambiental e reprodução social. In: Loureiro, C.F.B.; Layrargues, p.P. \& Castro, R.C. De (Orgs.) Pensamento complexo, dialética e educação ambiental. São Paulo: Cortez. p. 72-103. $2006 . \quad$ Disponível em: https://www.ifbaiano.edu.br/unidades/valenca/files/2011/05/MUITO-ALEM-DANATUREZA EDUCACAO-AMBIENTAL-E-REPRODUCAO-SOCIAL.pdf Acesso: 25 mai 2020.

- O cinismo da reciclagem: o significado ideológico da reciclagem da lata de alumínio e suas implicações para a educação ambiental. In: LOUREIRO, C.F.B., LAYRARGUES, P.P. \& CASTRO, R. de S. (Orgs.) Educação ambiental: repensando o espaço da cidadania. p. 179-219.São Paulo: Cortez. 2002. Disponível em: https://www.researchgate.net/publication/237655129 O CINISMO DA RECIC LAGEM o significado ideologico da reciclagem da lata de aluminio e sua s implicacoes para a educacao ambiental 1 Acesso: 25 mai 2020.

LIBÂNEO, J. C. Didática: teoria da instrução e do ensino. In: LIBÂNEO, J.C. Didática. São Paulo: Cortez, 1991.

LIMA, E. S. Educação do Campo, Currículo e Diversidades Culturais. Espaço do Currículo, v.6, n.3, p.608-619, Setembro a Dezembro de 2013. 
LIMA, G. F. C. Crise ambiental, educação e cidadania: os desafios da sustentabilidade emancipatória. In: LOUREIRO, C. F. B.; LAYRARGUES, P. P.; CASTRO, R. S. (Org.). Educação ambiental: repensando o espaço da cidadania. São Paulo: Cortez, 2002.

LOUREIRO, C. F. B. (Org.) Cidadania e meio ambiente. Salvador: Centro de Recursos Ambientais da Bahia, 2003. Cortez, 2004.

Trajetória e fundamentos da educação ambiental. São Paulo:

Complexidade e dialética: Contribuições à práxis política e emancipatória em Educação Ambiental. Educação e Sociedade, Campinas, vol. 27, n. 94, p. 131-152, jan./abr. 2006.

MARCUSCHI, L. A. Hipertexto e gêneros digitais. Rio de Janeiro: Lucerna, 2004.

MARIANI, B. ORLANDI, Eni Puccinelli. Análise do discurso - princípios e pro cedimentos. Campinas, Pontes, 1999. 100p. Rev. ANPOLL, n. 8, p. 213-219, jan./jun. 2000, Disponível em: https://revistadaanpoll.emnuvens.com.br/revista/article/view/357/366 Acesso: 28 mai 2020.

MELO, R. A.; LIMA, M. G. S. B.; COSTA, A. F. M. da. O currículo das escolas do campo e a articulação dos saberes da cultura camponesa aos conhecimentos escolares. Revista CAMINE: Caminhos da Educação, Franca, v. 6, n. 2, 2014. ISSN 2175-4217. Disponível em: https://ojs.franca.unesp.br/index.php/caminhos/article/view/1214/1238 Acesso: 21 mar 2020.

MINAYO M.C.S. O desafio do conhecimento: pesquisa qualitativa em saúde. São Paulo: Hucitec, 2008.

MOLINA, M. C. e SÁ, L. M. Escola do Campo. In: CALDART, R.S., PEREIRA, I. B., ALENTEJANO, P., FRIGOTTO, G. Dicionário da Educação do Campo. Rio de Janeiro, São Paulo: Escola Politécnica de Saúde Joaquim Venâncio, Expressão Popular, 2012. p. 324-331.

MOREIRA, A. F.; SILVA, T.T. Sociologia e teoria crítica do currículo: uma introdução. In:

Cortez, 1994. p. 7-37. (Orgs.). Currículo, cultura e sociedade. São Paulo:

MARCUSCHI, Luiz Antonio. Hipertexto e gêneros digitais. Rio de Janeiro: Lucerna, 2004.

OLIVEIRA, E. B.; PAIXÃO, G. S., SANTOS, F. N.; SAMPAIO, B. S. Temas geradores como contribuição metodológica para a prática docente. Kiri-kerê: Pesquisa em Ensino, n. 2, 2017. Disponível em: https://periodicos.ufes.br/kirikere/article/view/14300. Acesso em: 10 set. 2020. 
ORLANDI, E. P. Análise de Discurso: princípios e procedimentos. Campinas, SP: Pontes, 6 ${ }^{\text {a }}$ ed. 2005.

PAULA, J. L.; HENRIQUE, A. L.S. Educação Ambiental na Educação Profissional: caminhando em direção à formação humana integral. Revista Ensino Interdisciplinar, v. 2, p. 83-92, 2016. Disponível em: http://periodicos.uern.br/index.php/RECEl/article/view/1955/1054 Acesso: 25 mar 2020.

PRADO, M. E. B. B. Pedagogia de Projetos: Fundamentos e Implicações. In: ALMEIDA, M. E. B.; MORAN, J. M. (Org.). Integração das Tecnologias na Educação. Brasília, DF: Secretaria de Educação a Distância - Ministério de Educação-MEC, 2005, p. 12-17.

QUINTAS, J. S. Educação no processo de gestão ambienta: uma proposta de educação ambiental transformadora e emancipatória. In: LAYRARGUES, P. P (Coord.) Identidades da Educação Ambiental Brasileira. Brasília: Edições MMA - Ministério do Meio Ambiente, Diretoria de Educação Ambiental, 2004.

RACEFFAES. Regional das Associações dos Centros Familiares de Formação em Alternância do Espírito Santo: Cultivando a Educação dos Povos do Campo do Espírito Santo. São Gabriel da Palha, ES: [s.n.]. 2015.

RODRIGUES, J. A. Práticas discursivas de reprodução e diferenciação na Pedagogia da Alternância. Tese de Doutorado em Educação. UFES, Vitória, 2008. 190p.

ROSA, M. A. Desafios da educação ambiental nas escolas do campo. Cadernos de Pesquisa: Pensamento Educacional (Curitiba. Online), v. 10, p. 258-276, 2015.

SACRISTÁN, J. G. O Currículo: uma reflexão sobre a prática. 3.ed. Trad. Ernani F. da Fonseca Rosa. Porto Alegre: Artmed, 2000.

SANTOS, Lucíola. A construção do currículo: seleção do conhecimento escolar. Salto para o futuro. Currículo: conhecimento e cultura. Ano XIX, n 1, Abr. 2009.

SAVIANI, D. As Concepções Pedagógicas na História da Educação Brasileira. - Texto elaborado no âmbito do projeto de pesquisa "o espaço acadêmico da pedagogia no Brasil", financiado pelo CNPq, para o "projeto 20 anos do Histedbr". Campinas, 22 ago 2005.

ARPINI, N. Seca deixa 20 cidades do ES em situação 'extremamente crítica'. G1, Espírito Santo, 20 set. 2016. Disponível em: http://g1.globo.com/espiritosanto/noticia/2016/09/seca-deixa-20-cidades-do-es-estao-em-situacaoextremamente-critica.html Acesso em: 18 mai. 2020.

SILVA, T. T. Documentos de identidade; uma introdução às teorias do currículo. 2 ed. Belo Horizonte: Autêntica, 2005. 


\section{Sobre os Autores}

\section{Fernanda Tesch Coelho}

fernandac.tesch@gmail.com

Graduada em Licenciatura em Ciências Biológicas (2015), especialista em Educação do Campo (2016) pela Multivix - Campus São Mateus, mestrado em Ensino na Educação Básica (2017) pela Universidade Federal do Espírito Santo (UFES), campus Centro Universitário Norte do Espírito Santo (CEUNES). Atuou como professora substituta no CEUNES/UFES no período de 2018 a 2020. Atualmente, atua como professora contratada do ensino fundamental e médio pela Secretaria de Estado da Educação (SEDU) do estado do Espírito Santo.

\section{Marcos da Cunha Teixeira}

marcosteixeiraufes@gmail.com

Possui graduação em Licenciatura em Ciências Biológicas pela Universidade Federal do Espírito Santo (1997), mestrado em Entomologia/Ecologia pela Universidade Federal de Viçosa (1999) e doutorado em Entomologia/Ecologia pela Universidade Federal de Viçosa (2007). Atua no ensino superior desde 2001 e atualmente é professor adjunto do Departamento de Ciências Agrárias e Biológicas (DCAB) da Universidade Federal do Espírito Santo - Campus São Mateus onde coordena o Laboratório de Educação Ambiental do Núcleo de Práticas Pedagógicas em Biologia. Na UFES também é coordenador do Programa de Mestrado Profissional em Rede Nacional em Ensino de Biologia (PROFBIO). Entre 2009 e 2013 atuou como professor adjunto no Centro de Ciências Agrárias, Ambientais e Biológicas da Universidade Federal do Recôncavo da Bahia (UFRB) onde fundou e foi tutor do Programa Educação Tutorial Conexões de Saberes Socioambientais e orientou no Programa de mestrado em Gestão de Políticas Públicas. Desenvolve pesquisa e extensão em Ecologia, Educação ambiental e Ensino de ciências e Biologia. Franklin Noel dos Santos, Universidade Federal do Espírito Santo

\section{Franklin Noel dos Santos}

tornus@gmail.com

Professor Adjunto da Universidade Federal do Espírito Santo-UFES. Pós-doutor pela Universidade Federal do Pará/Petrobras. Doutor em Biociências Nucleares pela Universidade do Estado do Rio de Janeiro-UERJ. Mestre me Oceanografia Biológica pela Universidade Federal de Pernambuco-UFPE. Graduação em Ciências Biológicas pela Universidade Federal Rural de Pernambuco-UFRPE. 